\title{
A 180nm CMOS Capacitorless Low Drop-Out Regulator for Battery-operated Systems
}

\author{
Jorge Pérez Bailón, Belén Calvo, Nicolás Medrano, Pedro A. Martínez \\ Afiliación: Grupo de Diseño Electrónico (GDE) \\ Instituto de Investigación en Ingeniería de Aragón (I3A) \\ Universidad de Zaragoza, Mariano Esquillor s/n, 50018, Zaragoza, Spain. \\ Tel. +34-976762707, e-mail: 610686@unizar.es
}

\begin{abstract}
This paper presents a fully-integrated 180nm CMOS low drop-out regulator based on a simple telescopic cascode-compensated amplifier driving a PMOS pass-device. It provides a high precision $1.8 \mathrm{~V}$ output voltage for battery voltages from $3.6 \mathrm{~V}$ to $1.93 \mathrm{~V}$ up to a $50 \mathrm{~mA}$ load current with only $22 \mu \mathrm{A}$ quiescent current.
\end{abstract}

\section{Motivation}

The portable sensor market is pushing towards complete system-on-chip (SoC) solutions. One essential subsystem is the power management unit, where low drop-out (LDO) regulators play a key role delivering, under variations of load current $\mathrm{IL}_{\mathrm{L}}$ and battery voltage $\mathrm{V}_{\text {ВАт, }}$ a stable power supply $\mathrm{V}_{\text {out. }}$ The goal of this work is the design of a LDO regulator to power both the read out and actuation electronics of a battery-compatible front-end sensor interface based on integrated analog lock-in amplifiers [1], with the aim to attain a forthcoming SoC CMOS system. The LDO specifications are fixed to: design in a low cost $0.18 \mu \mathrm{m}$ CMOS process with an output voltage of $1.8 \mathrm{~V}$ from a $3.6 \mathrm{~V}$ battery-compatible input voltage, maximum load current of $50 \mathrm{~mA}$ and maximum $50 \mathrm{pF}$ load capacitor. Besides, it must comply with the two critical requirements of portable systems, i.e. reduced area and quiescent current, while maintaining good regulating performance, stability and fast response times, a challenging task with an on-chip approach [2].

\section{Proposed LDO}

The proposed LDO is shown in Figure 1. The external $\mathrm{V}_{\text {ref }}$ is set to $1.2 \mathrm{~V}$, the size of the PMOS pass transistor $\mathrm{M}_{\text {PASS }}$ is $(\mathrm{W} / \mathrm{L})=(9.5 \mathrm{~mm} / 0.34 \mu \mathrm{m})$, and the feedback resistances are $\mathrm{R}_{\mathrm{fb} 1}=60 \mathrm{k} \Omega$, $\mathrm{R}_{\mathrm{fb} 2}=120 \mathrm{k} \Omega$, realized using identical diodeconnected PMOS to optimize area. To attain high precision regulation with minimum power

This work was supported in part by MINECO-FEDER (TEC2015-65750-R) consumption, a single stage telescopic cascode error amplifier biased at $10 \mu \mathrm{A}$ is used. Cascode compensation, using a single $\mathrm{Cc}$ capacitor is adopted, thus achieving higher speed and power supply rejection (PSR) compared to the commonly used Miller compensation. To enhance the transient behaviour, a very simple dynamically biased current sink path is added, which is only active when the load current varies from high to low, helping to discharge the path formed by $\left(\mathrm{R}_{\mathrm{fb} 1}+\mathrm{R}_{\mathrm{fb} 2}\right)$ and $\mathrm{C}_{\mathrm{L}}$.

The LDO main performances are summarized on Table 1. It provides $1.8 \mathrm{~V}$ output with $0.008 \%$ precision for input voltages $\mathrm{V}_{\mathrm{BAT}}=1.93 \mathrm{~V}-3.6 \mathrm{~V}$ up to $50 \mathrm{~mA}$ load current with a total quiescent current of $22 \mu \mathrm{A}$. Line regulation is shown in Figure 2, for $\mathrm{I}_{\mathrm{L}}=50 \mathrm{~mA}$ (worst case); load regulation for $\mathrm{V}_{\mathrm{BAT}}=2.1 \mathrm{~V}$ (worst case) is shown in Figure 3. Figure 4 shows the open loop frequency performance with $\mathrm{Cc}=8.5 \mathrm{pF}$ to ensure $\mathrm{PM}>60^{\circ}$ over all the operating conditions. Figure 5 shows the full load transient response, displaying the benefit of the current sink path.

\section{Conclusions}

A high-performance fully-integrated LDO has been designed in $180 \mathrm{~nm}$ CMOS. Compared to previous implementations with similar specifications [2-3], it attains a good trade-off between regulation performance, power, size and time response.

\section{REFERENCES}

[1]. GARCIA-ROMEO, D., VALERO, M.R., MEDRANO, N., CALVO, B. and CELMA S. A High Performance LIA-Based Interface for Battery Powered Sensing Devices. Sensors-Basel, vol. 10, pp. 25260-25275, Sept. 2015.

[2]. MILLIKEN, R.J., SILVA-MARTINEZ, J. and SANCHEZ-SINENCIO, E. Full On-Chip CMOS Low-Dropout Voltage Regulator. IEEE Trans. Circuits Syst. I, Reg. Papers, vol. 54, no. 9, pp. 1879 1890, Sep. 2007.

[3]. CHEN, C. and HUNG C.C. A fast self-reacting capacitor-less low-dropout regulator, European Solid State Circuits Conference, pp.375-378, 2011. 


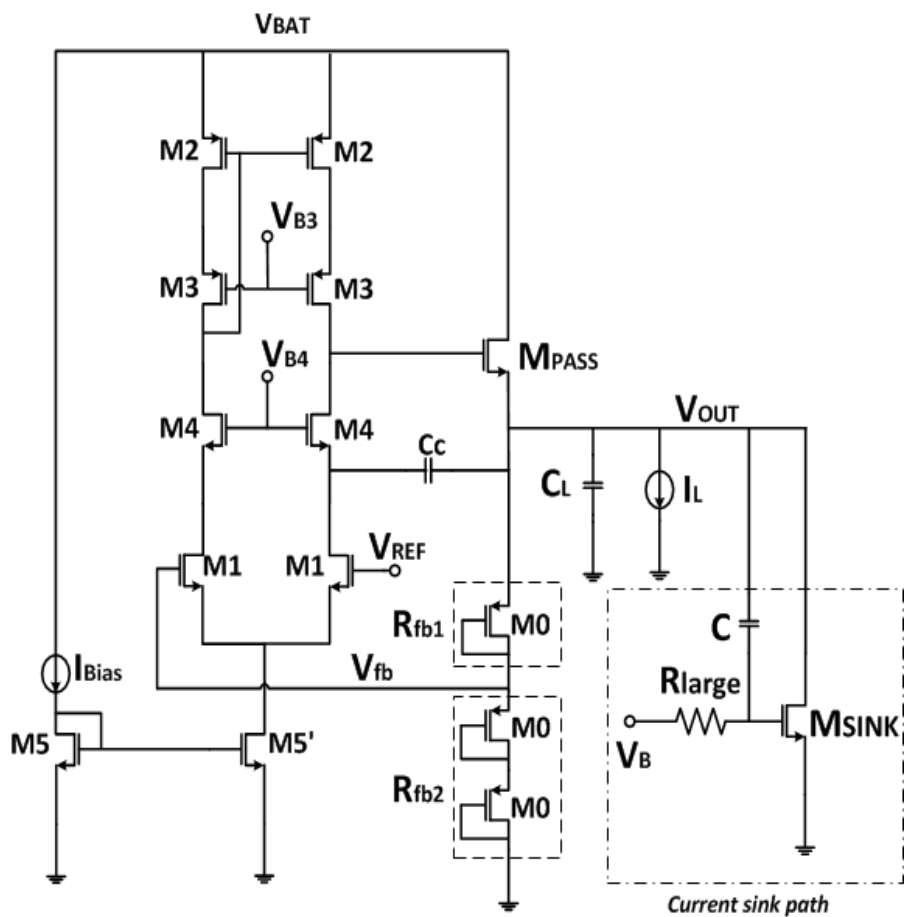

Figure 1: Schematic of the proposed CMOS LDO
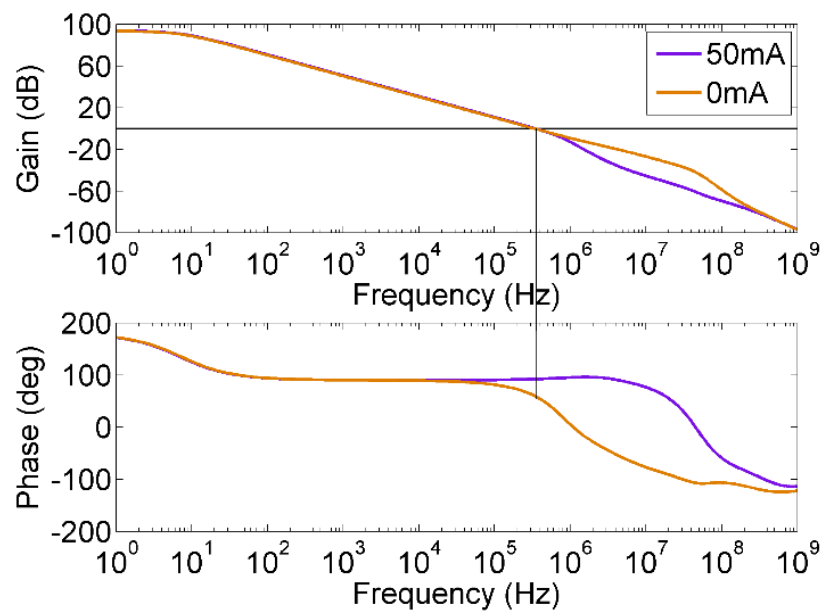

Figure 4: Open-loop frequency response, $V_{\mathrm{BAT}}=2.1 \mathrm{~V}$

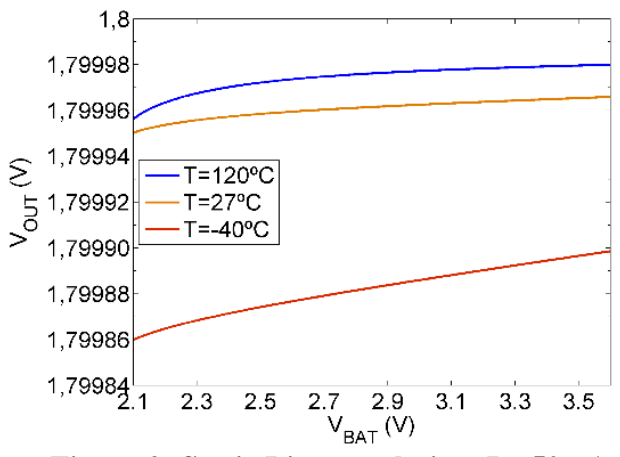

Figure 2: Static Line regulation, $I_{L}=50 \mathrm{~mA}$

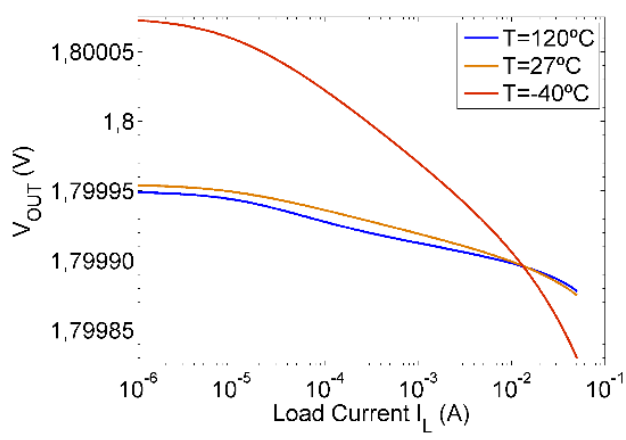

Figure 3: Static Load regulation, $\mathrm{V}_{\mathrm{BAT}}=\mathbf{2 . 1 \mathrm { V }}$
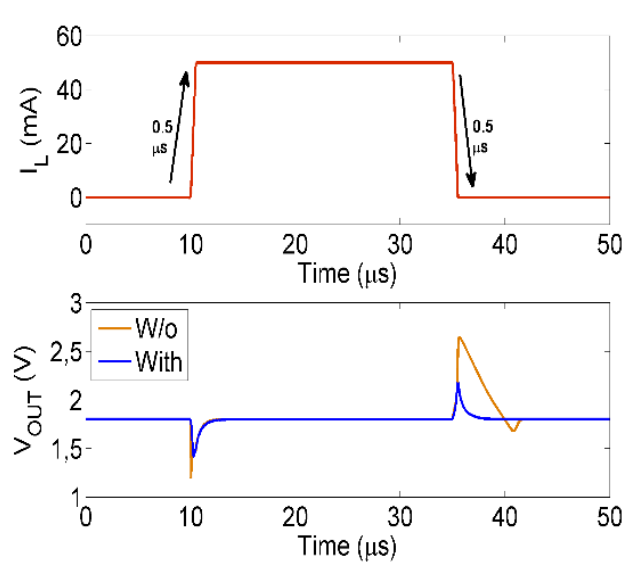

Figure 5: Full load transient w/o and with current sink path, $\mathrm{V}_{\mathrm{BAT}}=3.6 \mathrm{~V}$

Table 1: Comparison of CMOS capacitor-less LDO performances

\begin{tabular}{|l|l|l|l|}
\hline Parameter & This work, sim & {$[2], 2007, \exp$} & {$[3], 2011, \exp$} \\
\hline Technology $(\mu \mathrm{m})$ & 0.18 & 0.35 & 0.35 \\
\hline $\mathrm{V}_{\text {in }}(\mathrm{V})$ & $1.93-3.6$ & 3 & $1.642-5$ \\
\hline $\mathrm{V}_{\text {out }}(\mathrm{V})$ & 1.8 & 2.8 & 1.5 \\
\hline $\mathrm{V}_{\mathrm{do}}(\mathrm{mV}) @ \mathrm{I}_{\mathrm{L}, \max }$ & $130 @ 50 \mathrm{~mA}$ & $200 @ 50 \mathrm{~mA}$ & $142 @ 100 \mathrm{~mA}$ \\
\hline $\mathrm{I}_{\mathrm{q}}(\mu \mathrm{A})$ & 22 & 65 & 27 \\
\hline $\mathrm{C}_{\mathrm{L}}(\mathrm{pF})$ & 50 & 100 & 100 \\
\hline Line Regulation $(\mathrm{mV} / \mathrm{V})$ & 0.0087 & $\sim 23$ & 1.046 \\
\hline Load Regulation $(\mathrm{mV} / \mathrm{mA})$ & 0.0036 & $\sim 0.56$ & 0.0752 \\
\hline Full load settling time $(\mu \mathrm{s})$ & 3 & 15 & $1\left(\mathrm{I}_{\mathrm{L}}: 0\right.$ to $\left.100 \mathrm{~mA}\right)$ \\
\hline PSR $(\mathrm{dB})$ & $-62 @ 1 \mathrm{kHz}$ & $-57 @ 1 \mathrm{kHz}$ & $60.6 @ 1 \mathrm{kHz}$ \\
\hline
\end{tabular}

